Textures and Microstructures, Vol. 34, pp. 171-179 Reprints available directly from the publisher Photocopying permitted by license only
(C) 2000 OPA (Overseas Publishers Association) N.V.

Published by license under the Gordon and Breach Science Publishers imprint. Printed in Malaysia.

\title{
TEXTURE OF ELECTRODEPOSITED COPPER COATINGS AS RELATED TO THEIR SUBSTRUCTURE, GRANULAR STRUCTURE AND SURFACE MORPHOLOGY
}

\author{
O.B. GIRIN*, YU.O. PROSHENKO and E.P. KALINUSHKIN \\ State Metallurgical Academy of Ukraine, Prospekt Gagarina 4, \\ Dnipropetrovsk 320635, Ukraine
}

(Received 8 October 1999)

Results of comprehensive studies into crystallographic texture of electrodeposited copper coatings are presented in relation to their substructure, granular structure and surface morphology. Quantitative texture evaluation involving anisotropy of substructure characteristics, and determination of characteristics of substructure and granular structure in the axial and random components are addressed. Effects of texture anisotropy of substructure and texture nonhomogeneity of granular structure discovered in copper layers are dealt with. Influence of the deposition current density on quantitative characteristics of oriented structure in copper deposits is discussed. The effects of various thermodynamic factors on texture formation in copper electroplates are considered for the stages of (i) nucleation and (ii) growth of grains in the major component of texture. Anisotropy of shape is also treated for the elements of oriented structure in copper electrodeposits.

Keywords: Copper; Electrodeposition; Granular structure; Substructure; Texture; Anisotropy

\section{INTRODUCTION}

Recent work by Girin and Proshenko (1998) revealed that reliable data on the oriented structure in copper layers are of utmost importance for development of processes to make texturally composite and/or substructurally composite copper electrocoatings featuring improved

\footnotetext{
* Corresponding author.
} 
properties. The reason is that the electrocoating properties depend strongly on preferred orientation of the grains (Girin, 1995a) and on their substructure (Girin, 1995b) and lattice defects (Merchant and Girin, 1997).

Girin (1995b) demonstrated previously that in order to obtain reliable information on the oriented structure in coatings, interrelation between the texture, the substructure and the granular structure should be investigated. Nonconventional techniques developed for structural characterization of coatings allow such comprehensive investigation (Girin, 1998).

Review of the abundant literature on the texture (Lagiewka and Budniok, 1976; Rashkov and Stoichev, 1976; Andrianne et al., 1977; Mackinnon and Brannen, 1985; De Angelis et al., 1995), substructure (Hofer and Hintermann, 1965; Eichkorn and Fischer, 1966; Gamburg et al., 1974; Khaldeev and Kolevatova, 1978; Burov et al., 1984; De Angelis et al., 1995) and granular structure of copper electrocoatings (Hofer and Hintermann, 1965; Gamburg et al., 1974; Mamontov et al., 1976; Yasulaitene et al., 1979; Mamontov and Kurbatova, 1992) revealed marked contradictions among the available data. Some writers, e.g. Rashkov and Stoichev (1976) and Andrianne et al. (1977), demonstrated that [110] texture is the major one in electrolytic copper layers. On the other hand, Lagiewka and Budniok (1976) suggested that [111] texture was predominant while Mackinnon and Brannen (1985) believed that [133] texture was so. Rashkov and Stoichev (1976), furthermore, argued that a twinned texture with axes [411], [511], [771] and [755] may be found in electrodeposited copper in addition to the major component.

Neither is there a consensus on the dimensions of substructure elements copper electrocoatings. While Eichkorn and Fischer (1966) and Khaldeev and Kolevatova (1978) cited $500-600 \mathrm{~nm}$ as the size $D$ of mosaic blocks in copper coatings deposited at minimum overvoltages, Hofer and Hintermann (1965) and more recently Gamburg et al. (1974) gave values in a lower range, from 110 to $135 \mathrm{~nm}$. (Here, the mosaic blocks are regarded as regions of coherent scattering of X-rays.) A comparison of data on dislocation densities in copper electrocoatings shows that their values differ by one to two orders of magnitude (Burov et al., 1984; De Angelis et al., 1995).

The average grain size $d$ in copper coatings deposited under steadystate conditions was found by Mamontov et al. (1976) to be small at 
$1.5 \mu \mathrm{m}$; earlier, Gamburg et al. (1974) found it to be even as low as 0.1-0.3 $\mu \mathrm{m}$. On the other hand, Yasulaitene et al. (1979) reported that a coarse-grained structure with $d=14.5 \mu \mathrm{m}$ may form in copper electrocoats.

It is believed that the basic reason behind the inconsistencies in the literature data on texture, substructure and granular structure of copper layers is that the above characteristics of oriented structures were not studied in combination. The present study was therefore undertaken with a view to investigate formation of oriented structure in copper electrodeposits through examination of interrelationship of the texture, substructure and granular structure.

\section{EXPERIMENTAL}

Copper coatings $50 \mu \mathrm{m}$ thick were deposited from a stirred sulphate electrolyte at $25^{\circ} \mathrm{C}$ and current density varied from 0.5 to $9.5 \mathrm{~A} / \mathrm{dm}^{2}$ in steps of $1.5 \mathrm{~A} / \mathrm{dm}^{2}$. The coating texture was characterized using combined normal pole figures giving allowance for the substructure anisotropy. The substructure was previously studied for each of the various texture components individually (Girin, 1998). For quantitative representation of degree of texture, following quantities were used: $\alpha$, the average angle of texture dispersion; and $\eta$ and $\varepsilon$, the fraction of the axial and the random component respectively.

The coating substructure characteristics, namely the mosaic block size, the lattice distortions and the dislocation density, were measured along the [111] direction; measurements also were carried out along a certain direction taken at $35.3^{\circ}, 54.7^{\circ}$ or $0^{\circ}$ with respect to the coating normal for grains with a perfect [110] texture, a perfect [100] texture and for randomly oriented grains respectively. The block mosaic size was selected as the major characteristic of coating substructure while the quantity $\Delta D=D_{1}-D_{2}$ was used as a measure of texture anisotropy of the substructure, $D_{1}$ and $D_{2}$ being the average size of mosaic blocks for the grains with a perfect axial texture and with random orientation respectively. The average block size $D_{0}$ allowing for the coating degree of texture was defined as $\sum D_{1} \eta+D_{2} \varepsilon$.

The granular structure of the coatings was examined using brightfield transmission electron microscopy. The texture nonhomogeneity of 
granular structure was estimated as $d_{1} / d_{2}, d_{1}$ and $d_{2}$ being the average size of grains of the axial and the random component respectively. The average grain size allowing for the coating degree of texture was defined as $d_{0}=\sum d_{1} \eta+d_{2} \varepsilon$.

Conventional scanning electron microscopy and light microscopy techniques were employed to examine surface morphology and cross section microstructure of the coatings.

\section{RESULTS AND DISCUSSION}

The investigations revealed that an axial texture whose [110] axis is normal to the coating surface is predominant in copper layers deposited over a broad range of current densities from 0.5 to $8.0 \mathrm{~A} / \mathrm{dm}^{2}$. At current densities ranging from 5.0 to $8.0 \mathrm{~A} / \mathrm{dm}^{2}$, this is supplemented by an axial orientation whose [100] axis is normal to the coating surface, while a binary axial texture with the axes [211] and [310] forms at $9.5 \mathrm{~A} / \mathrm{dm}^{2}$. A fraction of grains in the copper layers under study was oriented at random. In all, the preferred orientations of the copper grains change with increasing current density as follows: [110], [110] $+[100]$, [211] $+[310]$. This series is almost identical to the one deduced from a thermodynamic model of electrocoating texture formation with the grain boundary energy as the key factor (Girin and Vorob'ev, 1991a; Girin, 1995a).

The combined approach to characterization of oriented structure revealed such effects as texture anisotropy of substructure and texture nonhomogeneity of granular structure in copper electrocoatings. The texture anisotropy is manifested by marked differences in the substructure characteristics measured along a certain crystallographic direction, e.g. [111], and at some component-specific angle to the normal to coating surface. The highest mosaic block sizes ranging from 405 to $480 \mathrm{~nm}$ and the lowest distortions of $(0.14 \ldots 0.20) \times 10^{-3}$ were found for grains with a perfect [110] texture. As the grain deviation from the [110] axis is increased, the mosaic block size is decreased while the lattice distortions rise to values characteristic of the random component $\left(330-300 \mathrm{~nm} ;(0.80 \ldots 0.53) \times 10^{-3}\right)$.

The texture anisotropy effect for copper electrocoating substructure is entirely different from the block shape anisotropy reported for copper coatings by De Angelis et al. (1995) and is found based on differences 
in block sizes along different crystallographic directions, namely [220] and [200]. The point is that the latter effect, also observed in copper powders with randomly oriented grains, is not related to texture.

The texture nonhomogeneity of granular structure discovered in copper layers is demonstrated in Fig. 1. The figure depicts granular structure in the various components of texture in a copper electrocoating. It is seen from Fig. 1(a) that the largest grains, $d=6.5 \mu \mathrm{m}$, are peculiar to the major [110] component (see Fig. 1(b)) for which $\eta_{[110]}=$ 0.30 and $\alpha_{[110]}=8.7^{\circ}$ (see Fig. 2A); a negligible defect density is another feature $\left(D_{[110]}=460 \mathrm{~nm}\right.$, see Fig. 2B). Smaller-size grains, $d=3.0 \mu \mathrm{m}$, make the secondary axial [100] component (see Fig. 1(c) and (d)) for

(a)

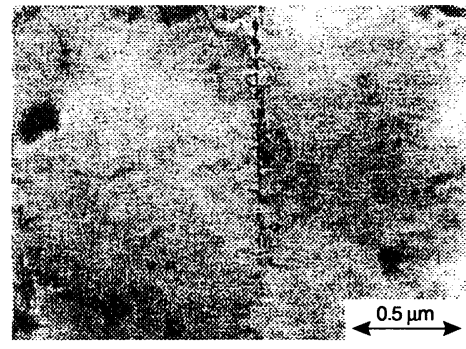

(c)

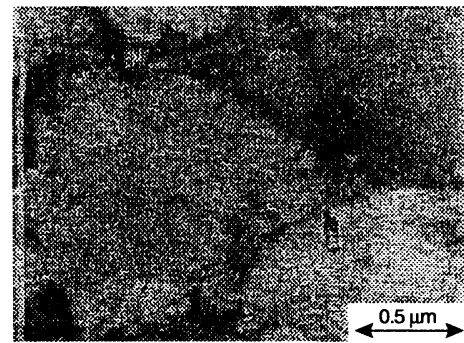

(e)

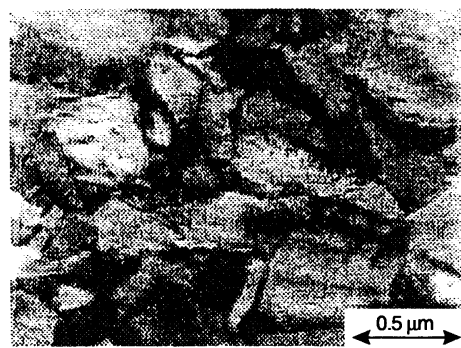

(b)

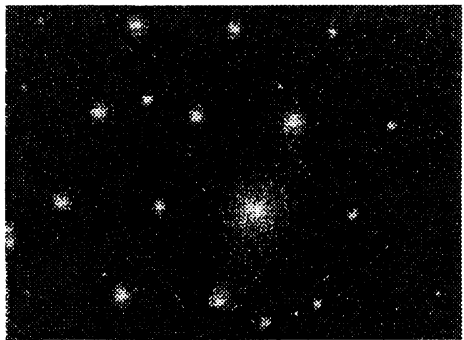

(d)

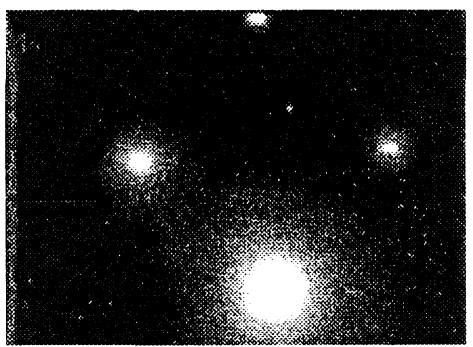

(f)

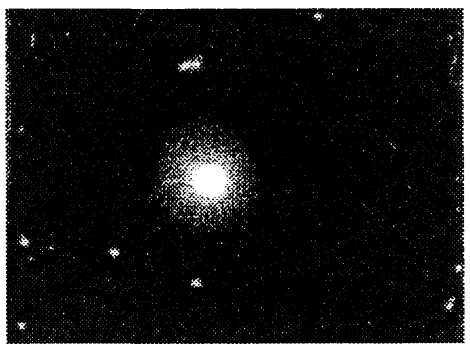

FIGURE 1 Electron micrographs (a, c,e) and corresponding electron diffraction patterns $(b, d, f)$ of the axial [110] $(a, b)$, the axial [100] $(c, d)$ and the random $(e, f)$ components of texture in a copper electroplate. $t=25^{\circ} \mathrm{C}$, current density $5.0 \mathrm{~A} / \mathrm{dm}^{2}$. 


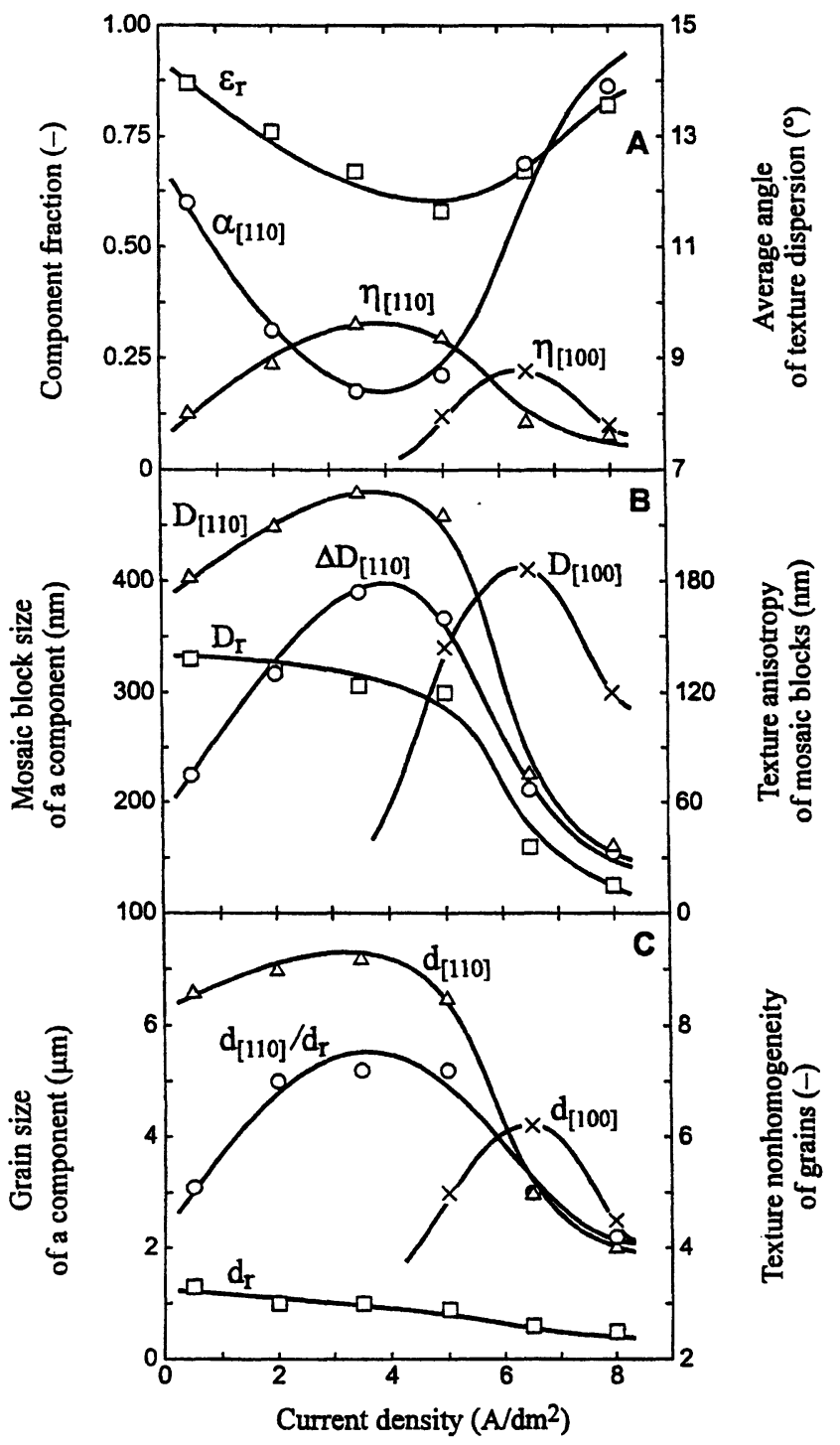

FIGURE 2 The major quantitative characteristics of texture (A) and substructure (B) and granular structure of the various texture components $(C)$ in copper electrocoatings as functions of current density. The notation is given in the text. 
which $\eta_{[100]}=0.12$ and $\alpha_{[100]}=12.4^{\circ}$ (see Fig. 2A); their defect density is somewhat higher $\left(D_{[100]}=340 \mathrm{~nm}\right.$, see Fig. 2B). The smallest grains, $d=0.9 \mu \mathrm{m}$ (Fig. 1(e)), having the highest defect densities compose the random component of texture, Fig. 1(f); $\varepsilon=0.58$, see Fig. $2 \mathrm{~A}$.

The integrated quantitative characterization of texture, substructure and granular structure revealed not only features of oriented structure formation in the various components of copper electrocoating texture, see Fig. 2, but also enabled estimation of its average characteristics allowing for the variation of degree of texture with the deposition current density, see Table I. In Fig. 2, the subscripts [110], [100] and r at symbols of properties correspond to the [110] and the [100] axial component and the random component respectively.

It follows from comparison of the data in Fig. 2 and Table I that the current density affects the formation of oriented structures in copper electrocoatings in a complex manner. As the current density is increased from 0.5 to $3.5 \mathrm{~A} / \mathrm{dm}^{2}$, the [110] axial texture becomes more nearly perfect and the average sizes of grains and mosaic blocks increase while the lattice distortions and dislocation densities decline. As the current density is further elevated to $8.0 \mathrm{~A} / \mathrm{dm}^{2}$, however, a marked decrease in the degree of texture is observed together with refinement of grains and blocks and increased lattice distortions and dislocation densities.

If the influence of texture is disregarded and only $D_{\mathrm{r}}$ and $d_{\mathrm{r}}$ are determined to characterize substructure and granular structure, erroneous conclusions regarding structure formation in electrodeposited copper are possible. That is, it may be concluded as it was done by Gamburg et al. (1974), Khaldeev and Kolevatova (1978) and Burov et al.

TABLE I Influence of the deposition current density on the average values of grain size $d_{0}$, mosaic block size $D_{0}$, lattice distortions $\Delta a / a_{0}$ and dislocation density $\rho_{0}$ in copper electrocoatings. The data allow for the degree of texture in a coating

\begin{tabular}{lcccc}
\hline $\begin{array}{l}\text { Current density } \\
\left(\mathrm{A} / \mathrm{dm}^{2}\right)\end{array}$ & $d_{0}(\mu \mathrm{m})$ & $D_{0}(\mathrm{~nm})$ & $\Delta a / a_{0}\left(\times 10^{-3}\right)$ & $\rho_{0}, \mathrm{~cm}^{-2}\left(\times 10^{9}\right)$ \\
\hline 0.5 & 2.0 & 331 & 0.63 & 2.74 \\
2.0 & 2.4 & 350 & 0.44 & 2.45 \\
3.5 & 3.0 & 363 & 0.34 & 2.28 \\
5.0 & 2.8 & 352 & 0.56 & 2.42 \\
6.5 & 1.7 & 227 & 2.00 & 5.82 \\
8.0 & 0.9 & 147 & 3.46 & 13.88 \\
\hline
\end{tabular}


(1984), that the grains and mosaic blocks are refined with increase in current density.

Based on a thermodynamic model of texture development in electrocoatings (Girin and Vorob'ev, 1991a; Girin, 1995a), the relative contributions of the grain boundary energy $\Delta F_{\mathrm{gb}}$, the surface energy $\Delta F_{\mathrm{s}}$ and the volume energy $\Delta F_{\mathrm{v}}$ to the driving force for formation of [110] axial texture in copper electroplates were estimated.

It was found that $\Delta F_{\mathrm{gb}}$ accounts for $98 \%$ while $\Delta F_{\mathrm{s}}$ and $\Delta F_{\mathrm{v}}$ each account for $1 \%$ of the driving force for nucleation of the major [110] component. On the other hand, the respective contributions of $\Delta F_{\mathrm{gb}}$, $\Delta F_{\mathrm{s}}$ and $\Delta F_{\mathrm{v}}$ to the driving force for the growth of the major [110] component are $46 \%, 1 \%$ and $53 \%$. Since the [110] axial texture is predominant in the copper deposits, it may be concluded that texture formation in copper electroplates is dominated by the following thermodynamic factors: (i) by the grain boundary energy at the stage of nucleation, and (ii) equally by the grain boundary energy and the volume energy at the stage of grain growth of the major component.

Considering the decisive role of the grain boundary energy in the formation of texture, the shape of nuclei was evaluated for the major [110] component in copper electrocoatings. The nuclei aspect ratio was found to be close to 4, indicating that the oriented structure is anisotropic with respect to both size and shape. Following conjecture can thus be made: as the texture develops due to accommodation and coalescence of grains of the major component (Girin and Vorob'ev, 1991 b; Girin, 1995a), the anisotropy of grain shape will become more pronounced, that is oriented growth will occur normal to the substrate surface and the grains will get coarser with increasing distance from the substrate.

Indeed, cross section micrographs and surface morphology show that oriented copper electrodeposits display columnar grains that are normal to substrate surface and progressively larger at a greater distance from the latter. A similar makeup of copper electroplates was previously observed on polished sections by Merchant (1995).

\section{References}

Andrianne, P.A., Dubois, J.P. and Winand, R.F.P. (1977). Electrocrystallization of copper in chloride aqueous solutions. Metallurgical Transactions, 8(B), 315-321.

Burov, L.M., Trofimenko, V.V., Zhitnik, V.P. and Loshkarev, Yu.M. (1984). Influence of polyacrylamide and acrylic acid additions on physical and mechanical properties of copper deposits. Ukrainskii Khimicheskii Zhurnal, 50, 962-967 (In Russian). 
De Angelis, R.J., Knorr, D.B. and Merchant, H.D. (1995). Through-thickness characterization of copper electrodeposit. In Defect Structure, Morphology and Properties of Deposits, edited by H.D. Merchant, pp. 87-102. Warrendale, PA: The Minerals, Metals and Materials Society.

Eichkorn, E. and Fischer, H. (1966). Zur roentgenografischen Untersuchung innerer Spannungen an elektrolytischen Metallniederschlagen, abgeschieden in Gegenwart von Inhibitoren. Zeitschrift. fuer Metallkunde, 57, 457-464 (In German).

Gamburg, Yu.D., Golubov, V.M., Knizhnik, G.S. and Polukarov, Yu.M. (1974). Structure of copper electrodeposited from a pyrophosphate solution. Elektrokhimiya, 10, 1492-1496 (In Russian).

Girin, O.B. (1995a). Texture development and texture/property relationsin electrodeposits. In Defect Structure, Morphology and Properties of Deposits, edited by H.D. Merchant, pp. 103-114. Warrendale, PA: The Minerals, Metals and Materials Society.

Girin, O.B. (1995b). Substructure formation and texture in electrodeposits. Journal of Electronic Materials, 24, 947-953.

Girin, O.B. (1998). Nonconventional X ray diffraction techniques for coating characterization. In Solidification 1998, edited by S.P. Marsh et al., pp. 161-169. Warrendale, PA: The Minerals, Metals and Materials Society.

Girin, O.B. and Proshenko, Yu.O. (1998). Some ways to synthesize new types of composite electrocoatings having enhanced properties. In Value-Addition Metallurgy, edited by W.D. Cho and H.Y. Sohn, pp. 277-283. Warrendale, PA: The Minerals, Metals and Materials Society.

Girin, O.B. and Vorob'ev, G.M. (1991a). A thermodynamic model of texture formation in electroplates. Izvestiya AN SSSR. Metally, 5, 119-127 (In Russian).

Girin, O.B. and Vorob'ev, G.M. (1991b). Mechanism of texture formation in electroplates. Izvestiya AN SSSR. Metally, 4, 161-167 (In Russian).

Hofer, L.M. and Hintermann, H.E. (1965). The structure of electrodeposited copper examined by X-ray diffraction techniques. Journal of Electrochemical Society, 112, 167-173.

Khaldeev, G.V. and Kolevatova, V.S. (1978). Structure and physical and mechanical properties of electrodeposited copper. Izvestiya AN SSSR. Metally, 6, 149-153 (In Russian).

Lagiewka, L. and Budniok, A. (1976). Struktura elektrolitycznie otrzymanych powlok miedzi. Rudy i metale niezelazove, 21, 59-63 (In Polish).

Mackinnon, D.J. and Brannen, J.M. (1985). Factors affecting the structure of copper deposits electrowon from aqueous chloride electrolyte. Journal of Applied Electrochemistry, 5, 649-658.

Mamontov, E.A. and Kurbatova, L.A. (1992). Formation of pentagonal grains in electrolytic copper deposits. Elektrokhimiya, 28, 746-753 (In Russian).

Mamontov, E.A., Kozlov, V.M. and Kurbatova, L.A. (1976). On the mechanism of lattice defect formation in electrolytic copper produced under non-steady-state conditions. Elektrokhimiya, 12, 508-512 (In Russian).

Merchant, H.D. (1995). Thermal response of electrodeposited copper. In Defect Structure, Morphology and Properties of Deposits, edited by H.D. Merchant, pp. 301-322. Warrendale, PA: The Minerals, Metals and Materials Society.

Merchant, H.D. and Girin, O.B. (1997). Defect structure and crystallographic texture of polycrystalline electrodeposits. In Electrochemical Synthesis and Modification of Materials, edited by P.C. Andricacos et al., Vol. 451, pp. 433-444. Pittsburgh, PA: Materials Research Society.

Rashkov, S. and Stoichev, D.S. (1976). Influence of some surface active additives on morphology and texture of copper electroplates. Izvestiya po Khimiya B'lgarska AN, 9, 633-652 (In Bulgarian).

Yasulaitene, V.V., Dzhyuve, A.P. and Matulis, Yu.Yu. (1979). Investigations into copper electroplate morphology during electrodeposit growth. In Studies in the Field of Metal Deposition, edited by Yu.Yu. Matulis, pp. 5-10. Vilnius: AN Litovskoi SSR (In Russian). 